\title{
Gastrointestinal physiological changes and their relationship to weight loss following
}

\section{the pose procedure}

J. C. Espinós ${ }^{1}$, R. Turró ${ }^{1}$, G. Moragas ${ }^{2}$, A. Bronstone ${ }^{3}$, J.N. Buchwald $^{3}$,

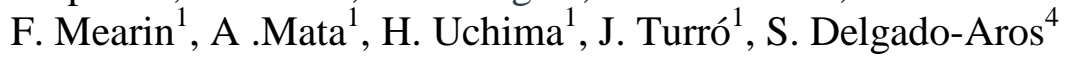

${ }^{1}$ Unidad de Endoscopia, Centro Médico Teknon, Barcelona, Catalonia, SPAIN

${ }^{2}$ CETIR Grup Médic Barcelona, Catalonia, SPAIN

${ }^{3}$ Division of Scientific Research Writing, Medwrite Medical Communications, Wisconsin, USA

${ }^{4}$ Neuro-Enteric Translational Science (NETS) Research Group, Institut Hospital del Mar d'Investigacions Mèdiques. IMIM Barcelona, Catalonia SPAIN

Word Count: 3,305 w/o refs

\section{Corresponding Author:}

Sílvia Delgado Aros, M.D., Ph.D., M.Sc.

Group Coordinator

Neuro-Enteric Translational Science (NETS)

IMIM-Parc de Salut Mar. PRBB

c/ Dr. Aiguader, 88

08003 Barcelona, Spain

Email: delgadoaross@gmail.com

Tel: +34932483058

Disclosure: Manuscript development was supported by USGI Medical, Inc. 


\section{Abstract}

Background and Aims The pose procedure is a novel bariatric endoscopic procedure which has been shown to reduce weight safely through 12 months. The study aimed to investigate the potential mechanisms of weight loss following the pose procedure.

Methods Patients with class I-II obesity received transmural plications in the gastric fundus and distal gastric body. Patients were evaluated before the procedure and at 2- and 6-month followup with solid gastric-emptying (GE) scintigraphy, a validated test of intake capacity (kcals) and plasma glucose homeostasis hormones/gastrointestinal (GI) peptides. Follow-up weight was recorded through 15 months. Regression modeling assessed variables that influenced percentage excess weight loss (\%EWL). Mean data and 95\% CIs are reported.

Results The pose procedure was performed on 18 patients (14F/4M); mean age 39 years (34; 44), body mass index (BMI, $\left.\mathrm{kg} / \mathrm{m}^{2}\right) 36$ (95\% CI, 35-37). At 15 months post-procedure, mean \%EWL was $63.7 \pm 25.1(95 \% \mathrm{CI}, 49.8 ; 77.6)$. Intake capacity at 2 and 6 months decreased significantly from $901(685 ; 1117)$ to $473(345 ; 600)$ and 574 kcals $(418 ; 730)$, respectively ( $\mathrm{p}<0.001)$. GE was delayed at 2 months but returned to baseline levels at 6 months. Glucose/insulin ratio improved $(\mathrm{p}<0.05)$. Postprandial decrease in ghrelin was enhanced $(\mathrm{p}=0.03)$ as well as postprandial increase in PYY $(\mathrm{p}=0.001)$. The best prediction model for \%EWL at 15 months after pose $\left(\mathrm{R}^{2}: 66 \%, \mathrm{p}=0.006\right)$ included pre-pose BMI, post-pose GE, and postprandial increase in PYY.

Conclusions The pose procedure was followed by significant, sustainable weight loss and improved glucose-homeostasis and satiation-peptide responses. Weight loss post procedure may be mediated through changes in gastrointestinal neuro-endocrine physiology. 
Keywords: pose; Incisionless Operating Platform; Bariatric Surgery; Weight loss; Satiety; Hormones; Glucose Homeostasis; Mechanism 


\section{Introduction}

Obesity is a major global health problem in the $21^{\text {st }}$ century. Although bariatric surgery has been shown to achieve long-term weight loss and comorbidity resolution superior to that of conventional obesity treatment (i.e., diet, exercise, pharmacotherapy) [1-3], and it is associated with a very low mortality rate $(0.1$ to $0.4 \%)$ [4,5], its use has been limited by concerns regarding morbidity and access [6]. Less-invasive approaches are needed.

The minimally invasive Incisionless Operating Platform ${ }^{\mathrm{TM}}$ (IOP; USGI Medical, San Clemente, CA, USA) has been used to carry out a variety of gastroendoscopic procedures, including the Repair of Surgery Endolumenal (ROSE) procedures to treat weight gain and repair complications following Roux-en-Y gastric bypass (RYGB). Recently, the IOP has been used as a platform to perform the pose procedure, which involves endolumenal placement of durable, full-thickness tissue plications in the fundus and additional plications in the distal body. In an earlier, prospective, single-center, observational study, 45 obese patients who received the pose procedure lost substantial weight (mean $49.4 \%$ EWL with $>80 \%$ achieving $\geq 25 \%$ EWL at 6 month follow-up) with no intraoperative adverse events, conversions, failed procedures, or postoperative re-hospitalizations [7]. In another pose study in 116 obese patients who were available for follow-up at 12 months, a mean EWL of $44.9 \%$ was attained with no serious adverse events [8].

There is no data yet on longer-term weight loss after pose. Moreover, the underlying mechanisms of weight loss after the pose procedure are unknown. It has been hypothesized that the pose 
procedure might induce weight loss by reducing caloric intake capacity (meal size). However, meal size depends on complex gastric and post-gastric neural and humoral signaling $[9,10]$. The procedure's plications in the fundus might limit postprandial fundus accommodation to a meal, which may increase intragastric pressure. Increased pressure might enhance the firing of gastric nerve endings, signaling satiation and prompting early meal termination $[11,12]$. It is also possible that distal gastric body plications placed with the pose procedure could impair antral contractions, delaying gastric emptying and further enhancing gastric satiation signals [13].

This study was designed to investigate specific mechanisms of weight loss following the pose procedure. Changes in meal size, gastric emptying, and gut hormones involved in short-term control of food intake and weight loss after pose were studied.

\section{Methods}

\section{Study and patients}

This was a single-center study of a prospective series of obese patients. All patients provided written informed consent prior to any study procedure in accordance with Teknon Medical Center (Barcelona, Spain) Ethics Board requirements and good clinical practices guidelines outlining patient protections stipulated by the Declaration of Helsinki. The study was registered as \#NCT01679158 in the United States clinicaltrials.gov database. 
Eligible patients were required to be $21-59$ years old with a BMI $\geq 30$ and $<40$. Patients were obliged to have had no significant weight change $( \pm 5 \mathrm{~kg})$ in the last 6 months. Patients were enrolled if they had: no contraindications for general anesthesia; successfully completed the physical and psychological assessment that confirmed their candidacy for a bariatric procedure; the ability to comply physically and mentally with the visit schedule and ancillary testing required for the study. Patients were also required to agree not to undergo any additional weightloss intervention, procedures, or liposuction for at least 18 months following study enrollment and not to take any prescription or over-the-counter weight-loss medications for at least one year after the pose procedure.

Patients were excluded if they had: a history of bariatric, gastric, or esophageal surgery; esophageal stricture or other anatomy and/or condition that could preclude passage of endolumenal instruments; moderate to severe gastroesophageal reflux disease; active peptic ulcer or hiatal hernia of $>3 \mathrm{~cm}$; gastrointestinal (GI) motility disorder or pancreatic insufficiency/disease; history of inflammatory disease of the GI tract; history of type 2 diabetes for $>2$ years or uncontrolled type 2 diabetes $\left(\mathrm{HbA}_{1 \mathrm{C}}>7.0\right)$; a history or current use of insulin or insulin derivatives for treatment of diabetes; severe coagulopathies, hepatic insufficiency, or cirrhosis; known hormonal or genetic cause for obesity; a history of, or current, drug or alcohol abuse; or had quit smoking within the last 6 months or planned to quit smoking in the next year. Also, patients were excluded if they were: currently taking medication for depression, psychosis, or other mood or eating disorder; currently taking corticosteroids; non-ambulatory or had significantly impaired mobility; pregnant; participating in another clinical study; or had worked for, or were a first-degree relative of, the investigator, study institution, or study support staff. 


\section{Study design}

In this study, the MOTIlity, Hormonal Impact, Satiety, and Weight Changes with VArying Procedural TEchniques (MOTIVATE) trial, patients underwent GI physiological studies (i.e., meal size, gastric emptying, glucose homeostasis, gut hunger/satiety peptides) at baseline (prior to the pose procedure), 2, and 6 months post-procedure. Weight, height, BMI, blood pressure, adverse events and changes in medications were recorded at baseline and at all post pose procedure follow-up evaluations at months $1,2,4,6,8,10,12$, and 15. In-office nutritional assessment and counseling were offered during follow up.

\section{Endoscopic equipment and surgical procedure}

The pose procedure is performed with a minimally invasive suite of gastroendoscopic instruments developed by USGI Medical (San Clemente, CA, USA) (Fig. 1a). The equipment and procedure have been described in detail in previous reports $[7,8]$.

Between 8 and 11 suture-anchor plications were placed with the IOP (Fig. 1b) in the fundus with the intent of forming two parallel rows, or "bridges" (Fig 1c); 3-4 additional suture-anchor plications were placed in the distal body using one of three techniques-(Fig. 1d) illustrates one of these techniques to help induce gastric dysmotility by reducing the size of the antral inlet.

\section{Postoperative care}

Patients were discharged within 24 hours, as deemed medically indicated. During the first 4 weeks post procedure, patients were advised to maintain a customized, calorie-restricted diet that 
transitioned from liquids to soft solids to full solids with a specified targeted amount of protein and fat and minimum quantity of liquids. Walking exercise (10-15 minutes 2-3 times/day) was encouraged during the first 4 postoperative weeks, and patients were encouraged to increase their exercise in the fifth week to an aerobic regimen of 30-45 minutes 5 times/week.

\section{Caloric intake capacity}

To assess caloric intake capacity (meal size) before and after the pose procedure, we used a standardized nutrient drink test $[11,14,15]$. Patients ingested a nutritional drink (Ensure ${ }^{\circledR}$, Abbott Nutrition, Lake Forest, IL; $1 \mathrm{~mL}=1.5 \mathrm{kcal}$ ) at a constant rate of $30 \mathrm{~mL} / \mathrm{minute}$. The glass was constantly filled with a perfusion pump so that the patient was unaware of the volume being ingested. Patients were instructed to maintain consumption at the fill rate and note their sensation of satiety using a graphical classification scale ranging from $0-5$ with verbal descriptors $(0=$ no symptoms; 5 = maximum fullness). Patients were told to stop ingestion when the score of 5 was reached. Caloric intake capacity was summarized as the number of calories ingested until the point of maximum satiation was reached.

Caloric intake measured by the nutrient drink test has been shown to correlate well with caloric intake during a buffet meal $[15,16]$. It has shown good reproducibility and sensitivity to change and has been tested in health, normal weight, and obese populations [17,18].

\section{Gastric emptying}

Gastric emptying of a solid meal was assessed using the gold standard measurement, scintigraphy $[13,19]$. As usual, patients attended the nuclear medicine department after 8 hours 
of fasting. They ingested a $400 \mathrm{kcal}$ standard meal (ham omelet $[20 \mathrm{~g}$ of ham, $50 \mathrm{~g}$ of egg, $5 \mathrm{~g}$ of oil], $20 \mathrm{~g}$ of bread, $7.5 \mathrm{~g}$ of butter, $12 \mathrm{~g}$ of marmalade, and $200 \mathrm{~mL}$ of fruit juice with the omelet marked with $1 \mathrm{mCi}(37 \mathrm{MBq})$ of 99mTc-DTPA. Anterior and posterior abdominal images of 2minute duration were obtained by means of a gamma camera at time 0 , every 10 minutes until 1 hour after the meal and every 20 minutes until 4 hours or no remaining gastric activity was seen.. Gastric emptying was summarized based on the proportion of food retained in the stomach (GR) at each time point.

\section{Glucose homeostasis and hunger/satiation peptides}

Fasting blood samples were collected through a venous cannula at baseline and 30, 60, 90, and 120 minutes after consumption of the $400 \mathrm{Kcal}$ standard meal (ham omelet [ $20 \mathrm{~g}$ of ham, $50 \mathrm{~g}$ of $\mathrm{egg}, 5 \mathrm{~g}$ of oil], $20 \mathrm{~g}$ of bread, $7.5 \mathrm{~g}$ of butter, $12 \mathrm{~g}$ of marmalade and $200 \mathrm{~mL}$ of fruit juice) to measure plasma levels of leptin, peptide-C, insulin, glucose, peptide YY (PYY3-36) and total ghrelin level.

Hormone measurements of PYY3-36 and total ghrelin were performed with radioimmunoassay, and leptin was measured using spectrophotometry (Diagnostics Biochem Canada, Inc., Ontario, Canada). Samples were collected using EDTA tubes, adding several commercial protease inhibitors to measure active hormones (Millipore DPPIV inhibitor, sigma protease inhibitor cocktail, and Pefabloc SC ${ }^{\circledR}$ [Roche Diagnostics, Mannheim, Germany).

Plasma changes in hunger/satiation peptides in response to a standard meal were summarized, as in previous studies $[15,17]$ by computing the ratio of the highest (lowest for ghrelin) postprandial 
plasma level over the fasting plasma level (Fed/Fast Ratio) and the postprandial proportional change (Fed-Fast /Fast x 100) for each hormone or peptide evaluated.

\section{Statistical analysis}

Patient baseline characteristics and operative outcomes were summarized using descriptive statistics. Continuous variables are reported as mean, standard deviation (SD), standard error (SE), and range. Outcome continuous variables are reported as mean (95\% CI). Categorical variables are reported as counts and percentages.

Excess body weight (EBW) at baseline was calculated as the difference between weight (kg) at baseline and ideal body weight (IBW). IBW was calculated for a BMI of 25. Weight loss after the pose procedure was assessed as proportional total body weight loss (\%TBWL) ([preprocedure weight minus post-procedure weight/pre-procedure weight] x 100) and proportional \%EWL ([pre-procedure weight minus post-procedure weight/pre-procedure EBW] x 100).

Postoperative changes were assessed using match-paired analyses. The specified primary endpoint for gastric emptying comparisons was, as in previous studies [17], initial gastric emptying; that is, gastric nutrients retained 10 minutes after the standard meal (GR10). Subgroup analyses for weight loss were not performed on the 3 distal body configurations due to the small sample size. 
Multivariate regression analyses were performed to identify significant independent predictors of $\%$ EWL at 15 months (dependent variable) following the procedure. We explored whether changes in meal size, GE, or hunger/satiation factors (independent variables) might predict sustained weight loss after the pose procedure. The primary endpoints selected for this analysis were, as used in previous studies [15,17], initial GR10 and plasma fasting levels and postprandial changes of hunger satiation hormones. The rational to select GR10 as primary gastric emptying endpoint was the hypothesis that meal size depends on signals that arise early during meal ingestion. We included as covariates age, sex, weight, height, and BMI. Regression models were explored using backward, forward, and mixed stepwise approaches selected based on the adjusted $\mathrm{R}^{2}$ with the least number of independent variables. Least-square mean estimates \pm SEM from the best-fitting regression model are reported.

\section{Results}

\section{Patient characteristics}

Between February and May 2012, the pose procedure was performed on 18 patients (14 women, 4 men) with a $100 \%(18 / 18)$ follow up at 6 months, $89 \%(16 / 18)$ at 9 months, and $83 \%(15 / 18)$ at both 12 and 15 months. Patients had a mean age of $39.3 \pm 9.8$ years (range, 21-53). The mean baseline weight and BMI were, respectively, $102.7 \pm 10.7 \mathrm{~kg}(89-131)$ and $36.3 \pm 2.3 \mathrm{~kg} / \mathrm{m}^{2}(32-$ 40). All patients reported overeating, and $67 \%(n=12)$, binge eating. 


\section{Operative outcomes}

The mean number of total suture anchors placed was $14.3 \pm 1.1(12-16)$, with a mean of $9.7 \pm 0.8$ (8-11) fundal anchors and $3.9 \pm 0.2(3-4)$ distal body anchors. The mean operative time was $51 \pm$ 9 minutes (39-70). All patients were discharged within 24 hours following the procedure. There were no postoperative complications or unscheduled endoscopies.

\section{Weight outcomes}

A significant and progressive weight loss after the pose procedure was maintained during the length of the entire study. Fig. 2 shows mean \%EWL and \%TBWL at baseline and during follow-up. At 15-month follow-up, mean $\%$ EWL was $63.7 \pm 25.1(95 \% \mathrm{CI}, 49.8 ; 77.6)$ and mean \% TBWL was $19.1 \pm 6.6(95 \% \mathrm{CI}, 15.5 ; 22.8)$. The respective proportion of patients who achieved at least 25\% EWL was $83 \%$ (15/18), 93\% (14/15), and 93\% (14/15) at 6, 12, and 15 months post-procedure.

\section{Caloric intake capacity}

Caloric intake capacity (meal size) was significantly reduced after the pose procedure. Thus, to reach maximum satiation, patients drank on average $901 \mathrm{kcals}(685 ; 1117)$ before and $473 \mathrm{kcals}$ $(345 ; 600)$ and $574(418 ; 730)$ at 2 and 6 months after the pose procedure, respectively (both p $<0.001$ vs. baseline) (Fig. 3).

\section{Gastric emptying}


Two months following the pose procedure, the gastric emptying rate was delayed during the first hour after the standard meal compared to before the pose procedure $(\mathrm{p}<0.05)$. However, on average, gastric emptying function completely normalized over 2 hours 6 months after pose (Fig. 4). All subjects emptied almost $100 \%$ by the 2 hour time-point.

\section{Glucose homeostasis and satiation peptides}

As might be expected, circulating leptin levels and glucose homeostasis improved after the pose procedure (Table and Fig. 5). Fasting and postprandial responses of ghrelin and PYY also improved. Hence, fasting levels of ghrelin increased 2 and 6 months after the pose procedure compared to baseline $(\mathrm{p}<0.05)$. Also, postprandial inhibition of ghrelin was significantly enhanced from $-7 \%$ before the procedure to $-15 \% 6$ months after the procedure $(\mathrm{p}=0.005)$. PYY fasting levels also decreased after the pose procedure vs. baseline $(\mathrm{p}<0.05)$ and postprandial PYY stimulation was significantly increased from $+15 \%$ to $+34 \% 6$ months after the pose procedure $(\mathrm{p}=0.04)$.

\section{Predictors of weight loss 15 months after pose}

As explained in the Methods, the physiological changes after the pose procedure were explored that might influence weight loss after surgery. Regression modeling was used that incorporated, as independent variables, sex, age, height, weight, BMI, GR10, and also plasma endocrine factors and hunger/satiation peptides during fasting and in the postprandial period. The bestfitting model for \%EWL 15 months post-procedure $\left(\mathrm{R}^{2}=66 \%\right.$; $\left.=0.006\right)$ included basal, preprocedure BMI, GR10, and PYY postprandial change 2 months post-procedure. Thus, weight 
loss at 15 months after the procedure was greater in lower-weight patients, those who experienced a greater GR10 at 2 months post-procedure, and those who experienced higher PYY postprandial change . Hence, independent of basal weight, greater impact on gastric function and postprandial PYY response 2 months after the pose procedure significantly influenced sustained weight loss. Fig. 6 shows the independent additive effects of postprandial PYY change and gastric retention on $\% \mathrm{EWL}$ at 15 months following the procedure.

\section{Discussion}

This small observational study was not intended to focus on weight measurement following the pose procedure, but rather to obtain insights into its mechanisms of action. However, the weight loss observed seems to support that of an earlier study that showed the pose procedure resulted in substantial weight loss in obese patients with 6 months of follow-up [7], and it suggests that this weight loss might be sustained at least through 15-month follow-up. In the MOTIVATE study, mean EWL at 6 and 15 months post-procedure was $56.5 \%$ and $63.7 \%$, respectively. The magnitude of weight loss following the pose procedure seems superior to that achieved with currently available pharmacotherapy and intensive lifestyle interventions [20], similar to that achieved with laparoscopic adjustable gastric banding (LAGB), and lower than that associated with RYGB at 12 months of follow-up [21,22]. Interestingly, the mean 15-month TBWL following the pose procedure $(19.1 \%)$ was significantly higher than the modest $5 \%$ TBWL shown to significantly reduce weight-related comorbidities, including diabetes, hypertension, and 
dyslipidemia [23]. At 15-month follow-up, >90\% (14/15) of evaluable patients and 78\% (14/18) of all enrolled patients (based on a conservative assumption that the 3 patients lost to follow-up before 15 months would have failed this endpoint) had achieved $\geq 25 \%$ EWL.

For the first time, the MOTIVATE study explored potential mechanisms underlying weight loss after the pose procedure. The data shows that there is a statistically significant post-procedure change in satiation (caloric intake capacity); thus, patients needed significantly fewer calories to reach the point of maximum satiation. This was observed early, at 2 months, and was maintained at 6 months post pose procedure. Caloric intake capacity as measured in this study has been shown to be a significant predictor of weight loss after RYGB or sleeve gastrectomy (LSG) [14]. Reduction in caloric capacity is critical to a successful and sustainable weight loss procedure. In addition to some reduction in gastric volume, it is hypothesized that the primary mechanism by which caloric intake is reduced is through the prevention of fundal accommodation by the suture anchors, triggering earlier satiety. The vast majority of pose procedure subjects at our facility continue to subjectively report earlier satiety and less hunger at 6 and 12 months post-procedure.

Satiation is known to depend on a complex array of gastric and post-gastric signals [21-23]. Meal size is influenced by gastric volume [11,12], gastric emptying, and the postprandial response of ghrelin and PYY [14]. In this study, circulating levels of both pre- and post-meal ghrelin and PYY were seen to change significantly after the pose procedure. These changes were observed as early as 2 months post-procedure and were maintained at 6 months, possibly contributing to early and sustained weight loss. 
Ghrelin is a gut peptide secreted primarily from the gastric fundus that stimulates appetite and increases food intake [24]. In normal-weight individuals, ghrelin increases before meals and decreases quickly afterwards [25]. The current study showed that pre-meal circulating ghrelin increased after the pose procedure. It has been shown that obese individuals have lower levels of circulating ghrelin [26] and that circulating ghrelin levels increase in response to weight loss by caloric restriction [27]. Thus, it is conceivable that observed changes in pre-meal circulating ghrelin may have been related to weight loss rather than to the pose procedure itself.

The MOTIVATE study also demonstrated that pre-meal circulating PYY levels decreased after pose, whereas postprandial PYY increased significantly at 2 and 6 months following the pose procedure. PYY, which signals satiety, is secreted from L cells located predominantly in the distal intestinal tract in response to nutrients [29]. Gastric emptying was not changed at $6 \mathbf{M}$ post-POSE compared to pre-POSE. Thus, gastric emptying would not explain the differences observed in our study on postprandial PYY levels after POSE. PYY is released within 10 minutes of food intake, before ingested nutrients reach the distal small intestine and colon where the greatest concentrations of PYY are found [Adrian TE, Ferri GL, BacareseHamilton AJ, FuessI HS, Polak JM, Bloom SR. Human distribution and release of a putative new gut hormone, peptide YY. Gastroenterology 1985;89:1070-1077.], Thus, suggesting that initial postprandial release of PYY is under neural control. Moreover, altered vagal afferent sensitivity has been suggested in obese patients [Dockray GJ. Gastrointestinal hormones and the dialogue between gut and brain. J Physiol 2014;592:2927-2941.]. Thus, it might be conceivable that improved vagal afferent 
sensitivity after POSE, as suggested after other bariatric interventions [Karamanakos SN, Vagenas K, Kalfarentzos F, Alexandrides TK. Weight loss, appetite suppression, and changes in fasting and postprandial ghrelin and peptide-YY levels after Roux-en-Y gastric bypass and sleeve gastrectomy: a prospective, double blind study. Ann Surg 2008;247:401-407.], might enhance PYY response to nutrients as observed in our study .

More interestingly, we observed that the postprandial PYY increase at 2 months was predictive of weight loss at 15 months. These findings are in concordance with the known biological functions of PYY [28] and with data from bariatric surgery studies [29-31].

Studies have shown better long-term weight outcomes after RYGB or laparoscopic adjustable gastric band LAGB in patients with enhanced PYY postprandial response [29-31]. The MOTIVATE study data suggest that increased PYY release in response to nutrients following the pose procedure may be a relevant mechanism of decreased caloric intake and the weight loss observed with this procedure, similar to that observed following several bariatric surgery techniques.

We also observed that patients show a transient delay of gastric emptying of solids early, 2 months after the pose procedure. This delay is conceivably the result of the physiological inflammatory response to the presence of transmural plications in the gastric wall. The presence of microinflammatory changes in the submucosal and muscular layers of the stomach alter sensory and motor responses in the gastrointestinal tract [32]. When inflammation resolves, gastric function may return to its previous state, as observed in the current study with the 
normalization of gastric emptying 6 months after the pose procedure. Interestingly, our data suggest that those who experienced transient delay in gastric emptying were more likely to lose more weight and to maintain their weight loss at 15-month follow-up. This observation should be considered with caution; however, once acute inflammation is resolved, permanent "sensitization" of afferent nerves in the gut wall may occur [33,34]. Peripheral sensitization is known to cause early satiation and increased postprandial fullness in many patients with functional dyspepsia $[35,36]$. Hence, it is not inconceivable that in patients undergoing the pose procedure who present more intense inflammatory responses at the gastric wall, and thus, a transient delay in gastric emptying, sensitization may occur that might explain permanent enhanced satiation perception in response to food. Additional studies of the pose procedure's mechanisms of action are needed to clarify this issue.

In conclusion, the MOTIVATE study provides additional evidence that the endoscopic pose procedure results in substantial early weight loss sustained through 15 months. Further, the study suggests that potential mechanisms of weight loss following the pose procedure may include significant changes in neuro-hormonal circuits involved in the regulation of food intake. Additional research with larger sample sizes and longer follow-up is needed to determine the efficacy of the pose procedure in promoting durable weight loss and resolving obesity related comorbidities as well as to establish the procedure's therapeutic profile and cost-effectiveness compared with bariatric surgical procedures. 


\section{Acknowledgments}

We wish to thank Mónica Isart Rueda, Director of Lab services at Teknon, Javier Pavia for assistance with gastric emptying analysis, and Maribel Sánchez for nutritional support during the study.

Disclosure: Manuscript development was financially supported by USGI Medical, Inc., USA. A. Bronstone is a Scientific Research Writer and J. N. Buchwald is Director and Chief Scientific Research Writer at Medwrite LLC, a CRO under contract with USGI. 


\section{References}

1. Colquitt JL, Picot J, Loveman E, Clegg AJ. Surgery for obesity. Cochrane Database Syst Rev 2009(2): Cd003641.

2. Ribaric G, Buchwald JN, McGlennon TW. Diabetes and weight in comparative studies of bariatric surgery vs conventional medical therapy: a systematic review and meta-analysis. Obes Surg 2014; 24(3): 437-55

3. Schauer PR, Kashyap SR, Wolski K, Brethauer SA, et al. Bariatric surgery versus intensive medical therapy in obese patients with diabetes. N Engl J Med 2012; 366(17): $1567-76$

4. Buchwald H, Estok R, Fahrbach K, Banel D, Sledge I. Trends in mortality in bariatric surgery: a systematic review and meta-analysis. Surgery 2007; 142(4): 621-32; discussion 32-5

5. Chang SH, Stoll CR, Song J, Varela JE, et al. The effectiveness and risks of bariatric surgery: an updated systematic review and meta-analysis, 2003-2012. JAMA Surg 2014; 149(3): $275-87$

6. Martin M, Beekley A, Kjorstad R, Sebesta J. Socioeconomic disparities in eligibility and access to bariatric surgery: a national population-based analysis. Surg Obes Relat Dis $2010 ; 6(1): 8-15$

7. Espinos JC, Turro R, Mata A, Cruz M, et al. Early experience with the Incisionless Operating Platform (IOP) for the treatment of obesity: the Primary Obesity Surgery Endolumenal (POSE) procedure. Obes Surg 2013; 23(9): 1375-83 
8. Lopez-Nava G, Bautistia-Castaño I, Jiminez A, de Grado T, et al. The Primary Obesity Surgery Endolumenal (POSE) Procedure: one-year patient weight loss and safety outcomes. Surg Obes Relat Dis 2014, in press

9. Woods SC. Gastrointestinal satiety signals I. An overview of gastrointestinal signals that influence food intake. Am J Physiol Gastrointest Liver Physiol 2004; 286(1): G7-13

10. Morton GJ, Meek TH, Schwartz MW. Neurobiology of food intake in health and disease. Nat Rev Neurosci 2014 Jun; 15(6): 367-78

11. Delgado-Aros S, Cremonini F, Castillo JE, Chial HJ, et al. Independent influences of body mass and gastric volumes on satiation in humans. Gastroenterology 2004; 126: 43240

12. Vazquez Roque MI, Camilleri M, Stephens DA, Jensen MD, et al. Gastric sensorimotor functions and hormone profile in normal weight, overweight, and obese people. Gastroenterol 2006; 131: 1717-24

13. Moragas G, Azpirov F, Pavia J, Malagelada JR. Relations among intragastric pressure, postcibal perception, and gastric emptying. Am J Physiol 1993 June; 246(6 Part 1): G1112-7

14. Gras-Miralles B, Haya JR, Moros JM, Goday-Amo A, et al. Caloric intake capacity as measured by a standard nutrient drink test helps to predict weight loss after bariatric surgery. Obes Surg 2014; Dec24(12): 2138-44

15. Puigvehi M, Gras-Miralles B, Torra S, Alsina S, et al. Comparison of ad-libitum energy intake and the neuro-endocrine postprandial response as measured during a buffet-type meal and a standardized nutrient drink test. Gastroenterology 2012; 142: S-56 
16. Puigvehi M, Gras-Miralles B, Torra S, Ibanez IA, et al. In press, 2014.

17. Torra S, Ilzarbe L, Malagelada JR, Negre M, et al. Meal size can be decreased in obese subjects through pharmacological acceleration of gastric emptying (The OBERYTH trial). Int J Obes (Lond) 2011 Jun; 35(6): 829-37

18. Meyer-Gerspach AC, Wölnerhanssen B, Beglinger B, Nessenius F, et al. Gastric and intestinal satiation in obese and normal weight healthy people. Physiol Behav 2014 April 22; $129: 265-71$

19. Camilleri M, Colemont LJ, Phillips SF, Brown $M L$, et al. Human gastric emptying and colonic filling of solids characterized by a method. Am J Physiol 1989 Aug; 257(2 Part 1): G284-90

20. Ginsberg GG, Chand B, Cote GA, Dallal RM, et al. A pathway to endoscopic bariatric therapies. Gastrointest Endosc 2011; 74(5): 943-53

21. Buchwald H, Avidor $Y$, Braunwald E, et al. Bariatric surgery: a systematic review and meta-analysis. JAMA 2004; 292(14): 1724-37

22. Buchwald H, Estok R, Fahrbach K, Banel D, et al. Weight and type 2 diabetes after bariatric surgery: systematic review and meta-analysis. Am J Med 2009; 122(3): 248-56

23. Wilson PW, Kannel WB, Silbershatz H, D'Agostino RB. Clustering of metabolic factors and coronary heart disease. Arch Intern Med 1999; 159(10): 1104-9

24. Date Y, Kojima M, Hosoda H, Sawaguchi A, et al. Ghrelin, a novel growth hormonereleasing acylated peptide, is synthesized in a distinct endocrine cell type in the gastrointestinal tracts of rats and humans. Endocrinology 2000; 141(11): 4255-61 
25. Cummings DE, Purnell JQ, Frayo RS, Schmidova K, et al. A preprandial rise in plasma ghrelin levels suggests a role in meal initiation in humans. Diabetes 2001; 50(8): 1714-9

26. Tschop M, Weyer C, Tataranni PA, Devanarayan $V$, et al. Circulating ghrelin levels are decreased in human obesity. Diabetes 2001; 50(4): 707-9

27. Cummings DE, Weigle DS, Frayo RS, Breen PA, et al. Plasma ghrelin levels after dietinduced weight loss or gastric bypass surgery. N Engl J Med 2002; 346(21): 1623-30

28. Batterham RL, Cohen MA, Ellis SM, le Roux CW, et al. Inhibition of food intake in obese subjects by peptide YY3-36. N Engl J Med 2003; 349(10): 941-8

29. Morinigo R, Vidal J, Lacy AM, Delgado S, et al. Circulating peptide YY, weight loss, and glucose homeostasis after gastric bypass surgery in morbidly obese subjects. Ann Surg 2008; 247(2): 270-5

30. le Roux $C W$, Welbourn R, Werling $M$, Osborne A, et al. Gut hormones as mediators of appetite and weight loss after Roux-en-Y gastric bypass. Ann Surg 2007; 246(5): 780-5

31. Korner J, Inabnet W, Conwell IM, Taveras $C$, et al. Differential effects of gastric bypass and banding on circulating gut hormone and leptin levels. Obesity (Silver Spring) 2006; 14(9): 1553-61

32. Lakhan SE, Kirchgessner A. Neuroinflammation in inflammatory bowel disease. J Neuroinflamm 2010; 7: 37

33. Woolf CJ, Salter MW. Neuronal plasticity: increasing the gain in pain. Science 2000; 288: $1765-9$

34. Cervero F, Laird JM. Visceral pain. Lancet 1999; 353: 2145-8 
35. Tack J, Demedts I, Dehondt G, Caenapeel P, et al. Clinical and pathophysiological characteristics of acute-onset functional dyspepsia. Gastroenterol 2002; 122: 1738-47

36. Mearin F, Perez-Oliveras M, Perello A, Vinyet J, et al. Dyspepsia and irritable bowel syndrome after a Salmonella gastroenteritis outbreak: one-year follow-up cohort study. Gastroenterol 2005; 129: 98-104 


\section{Figure Legend}

Fig. 1. (a) Incisionless Operating Platform ${ }^{\mathrm{TM}}$ with TransPort ${ }^{\circledR}$ Endoscopic Access Device; (b) target tissue approximation using the g-Cath $\mathrm{EZ}^{\mathrm{TM}}$ Suture Anchor Delivery Catheter; (c) pose suture anchor plications in gastric fundus; (e) pose suture anchor plications in distal body.

Fig. 2. Weight-loss outcomes.

Fig. 3. Mean caloric intake required to reach maximum satiation (meal size) before surgery and at 2 and 6 months after surgery. Note that meal size was significantly lower at $2(\mathrm{p}<0.001)$ and 6 months $(\mathrm{p}<0.001)$ following the procedure compared with baseline.

Fig. 4. Gastric emptying curves pre-pose and at 2 and 6 months after pose. Two months after surgery, gastric emptying was prolonged during the first 60 minutes after a meal compared with pre-surgery. By 6-month follow-up, patients' gastric emptying profile was similar to their preprocedure profile.

Fig. 5. Surface plot showing the independent effects of postprandial increase in PYY ( $\triangle P Y Y)(x$ axis) and at 10 minutes post-meal gastric retention (GR10) (z axis) on percentage excess weight loss (\%EWL) (black surface) at 15 months after pose. Note that weight loss is greater in those 
26

with higher postprandial $\triangle \mathrm{PYY}$ and those with increased GR10 (arrow). On the contrary, weight loss is lower in those with a lesser increase in postprandial $\triangle \mathrm{PYY}$ and decreased GR10 (arrowhead). 


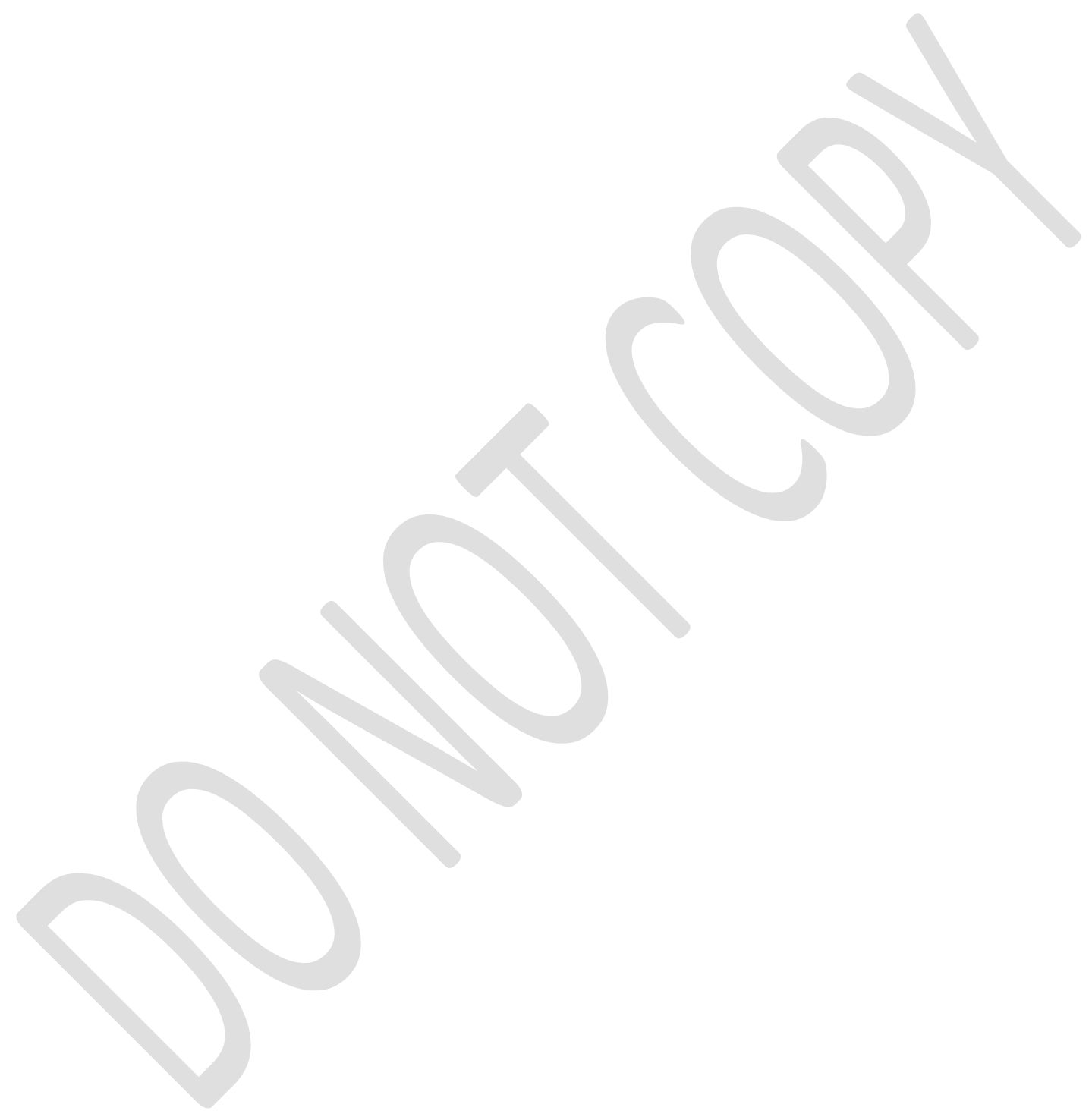


Table. Plasma levels of glucose homeostasis and hunger/satiation peptides pre-pose, 2, and 6 months post-pose procedure.

\begin{tabular}{llllll}
\hline & Pre-pose & $\begin{array}{l}\text { 2 months } \\
\text { post-pose }\end{array}$ & $\begin{array}{l}\text { P (compared } \\
\text { to pre-pose) }\end{array}$ & $\begin{array}{l}\text { 6 months } \\
\text { post-pose }\end{array}$ & $\begin{array}{l}\text { P (compared } \\
\text { to pre-pose) }\end{array}$ \\
\hline Leptin & $52(40 ; 63)$ & $20(13 ; 28)$ & $<0.0001$ & $31(18 ; 44)$ & 0.0003 \\
Peptide-C fast & $3.03(2.4 ; 3.7)$ & $2.3(1.4 ; 3.2)$ & 0.18 & $1.9(1.6 ; 2.3)$ & 0.003 \\
Insulin fast & $12.7(8.2 ; 17.3)$ & $5.3(2.5 ; 8.1)$ & 0.0003 & $9.3(6.8 ; 11.8)$ & 0.11 \\
Glucose fast & $105(92 ; 117)$ & $92(87 ; 96)$ & 0.02 & $92(87 ; 97)$ & 0.01 \\
Glucose fed & $145(124 ; 166)$ & $127(116 ; 138)$ & 0.04 & $126(112 ; 139)$ & 0.007 \\
Ghrelin fast & $618(522 ; 713)$ & $702(587 ; 818)$ & 0.02 & $755(576 ; 934)$ & 0.04 \\
PYY fast & $102(87 ; 116)$ & $73(58 ; 88)$ & 0.005 & $79(60 ; 97)$ & 0.03 \\
PP ghrelin $\Delta$ & $-7 \%(-4,-10)$ & $-18 \%(-10 ;-26)$ & 0.04 & $-15 \%(-11 ;-18)$ & 0.005 \\
PP PYY $\Delta$ & $+15 \%(7 ; 29)$ & $+56 \%(30 ; 81)$ & 0.007 & $+34 \%(11 ; 57)$ & 0.04 \\
PP ghrelin ratio & $0.9(0.9 ; 1)$ & $0.8(0.7 ; 0.9)$ & 0.04 & $0.8(0.8 ; 0.9)$ & 0.005 \\
PP PYY ratio & $1.15(1 ; 1.3)$ & $1.6(1.3 ; 1.8)$ & 0.007 & $1.3(1.1 ; 1.6)$ & 0.04 \\
\hline
\end{tabular}

pose, primary obesity surgery endolumenal; $\Delta$, change.

Fast: plasma levels measured in fasting conditions; Fed: maximum (minimum for ghrelin) levels during the fed period $(2 \mathrm{~h}$ ) measured; PP ratio: postprandial ratio (fed/fast); PP $\Delta$ : postprandial delta (fed-fast/fast X 100).

1. Karamanakos SN, Vagenas K, Kalfarentzos F, Alexandrides TK. Weight loss, appetite suppression, and changes in fasting and postprandial ghrelin and peptide-YY levels after Roux-en-Y gastric bypass and sleeve gastrectomy: a prospective, double blind study. Ann Surg. Mar 2008;247(3):401-407.

2. De Silva A, Bloom SR. Gut Hormones and Appetite Control: A Focus on PYY and GLP-1 as Therapeutic Targets in Obesity. Gut Liver. Jan 2012;6(1):10-20.

1. Dockray GJ. Gastrointestinal hormones and the dialogue between gut and brain. J Physiol. Jul 15 2014;592(Pt 14):2927-2941. 
2. Karamanakos SN, Vagenas K, Kalfarentzos F, Alexandrides TK. Weight loss, appetite suppression, and changes in fasting and postprandial ghrelin and peptide-YY levels after Roux-en-Y gastric bypass and sleeve gastrectomy: a prospective, double blind study. Ann Surg. Mar 2008;247(3):401-407.

3. De Silva A, Bloom SR. Gut Hormones and Appetite Control: A Focus on PYY and GLP-1 as Therapeutic Targets in Obesity. Gut Liver. Jan 2012;6(1):10-20.

1. Karamanakos SN, Vagenas K, Kalfarentzos F, Alexandrides TK. Weight loss, appetite suppression, and changes in fasting and postprandial ghrelin and peptide-YY levels after Roux-en-Y gastric bypass and sleeve gastrectomy: a prospective, double blind study. Ann Surg. Mar 2008;247(3):401-407.

2. De Silva A, Bloom SR. Gut Hormones and Appetite Control: A Focus on PYY and GLP-1 as Therapeutic Targets in Obesity. Gut Liver. Jan 2012;6(1):10-20. 